\title{
Specific mutations in the permease domain of septal protein SepJ differentially affect functions related to multicellularity in the filamentous cyanobacterium Anabaena
}

\author{
Félix Ramos-León ${ }^{1}$, Sergio Arévalo ${ }^{1}$, Vicente Mariscal ${ }^{1}$ and Enrique Flores ${ }^{1, *}$ \\ ${ }^{1}$ Instituto de Bioquímica Vegetal y Fotosíntesis, CSIC and Universidad de Sevilla, Américo Vespucio 49, E-41092 Seville, Spain. \\ * Corresponding Author: \\ Enrique Flores, Instituto de Bioquímica Vegetal y Fotosíntesis, CSIC and Universidad de Sevilla, Américo Vespucio 49, E-41092 Seville, \\ Spain; E-mail: eflores@ibvf.csic.es
}

\begin{abstract}
Filamentous, heterocyst-forming cyanobacteria are multicellular organisms in which growth requires the activity of two interdependent cell types that exchange nutrients and regulators. Vegetative cells provide heterocysts with reduced carbon, and heterocysts provide vegetative cells with fixed nitrogen. Additionally, heterocyst differentiation from vegetative cells is regulated by inhibitors of differentiation produced by prospective heterocysts and heterocysts. Proteinaceous structures known as septal junctions join the cells in the filament. The SepJ protein is involved in formation of septal junctions in the model heterocyst-forming cyanobacterium Anabaena sp. strain PCC 7120. SepJ bears extra-membrane and membrane (permease) domains and is located at the cell poles in the intercellular septa of the filament. Here we created Anabaena mutants that produce SepJ proteins altered in the permease domain. Some of these mutant SepJ proteins did not provide functions needed for Anabaena to form long filaments and (in some cases) differentiate heterocysts, identifying amino acids and amino acid stretches that are important for the structure or function of the protein. Some other mutant SepJ proteins fulfilled filamentation and heterocyst differentiation functions but failed to provide normal communication function assessed via the intercellular transfer of the fluorescent marker calcein. These mutant SepJ proteins bore mutations in amino acids located at the cytoplasmic face of the permease, which could affect access of the fluorescent marker to the septal junctions. Overall, the data are consistent with the idea that SepJ carries out multiple roles in the multicellular function of the Anabaena filament.
\end{abstract}

doi: $10.15698 /$ mic2018.12.661

Received originally: 11.07.2018;

in revised form: 03.09.2018,

Accepted 13.09.2018,

Published 16.10.2018.

Keywords: Anabaena, bacterial development, intercellular communication, multicellularity, nitrogen fixation.
Abbreviations:
FRAP-fluorescence recovery after photobleaching,
TMS - transmembrane segment.

\section{INTRODUCTION}

Heterocyst-forming cyanobacteria grow as chains of vegetative cells that fix $\mathrm{CO}_{2}$, performing oxygenic photosynthesis. Under nitrogen deprivation, some vegetative cells in the filament differentiate into $\mathrm{N}_{2}$-fixing heterocysts producing a pattern of two heterocysts separated by about ten vegetative cells [1]. In the model heterocyst-forming cyanobacterium Anabaena sp. strain PCC 7120 (hereafter Anabaena), differentiation requires the activity of the NtcA and HetR transcription factors [2], and differentiation of an excessive number of heterocysts appears to be prevented by diffusible inhibitors produced by prospective heterocysts (proheterocysts) and heterocysts [1]. This inhibition involves possible morphogens related to products of the
patS and hetN genes [3-5]. In the mature diazotrophic filament, heterocysts and vegetative cells exchange nutrients, resulting in a net transfer of reduced carbon to heterocysts and of fixed nitrogen to vegetative cells $[1,6]$. Exchanged nutrients likely include sucrose transferred from vegetative cells to heterocysts (see [7], and references therein), and glutamine and the dipeptide $\beta$-aspartyl arginine transferred from heterocysts to vegetative cells (see [8], and references therein).

In heterocyst-forming cyanobacteria, intercellular molecular transfer has been traced by fluorescence recovery after photobleaching (FRAP) analysis with fluorescent markers including calcein [9], 5-carboxyfluorescein [10] and the sucrose analog esculin [7]. Intercellular movement 
of the fluorescent markers appears to occur by simple diffusion $[7,9,11]$. The cells in the filament are connected by septal junctions $[1,12,13]$, previously known as microplasmodesmata [14] or septosomes [15]. These are proteinaceous structures that likely traverse the septal peptidoglycan through perforations termed nanopores [16] or channels [17]. Proteins that contribute to the formation of septal junctions include SepJ [18], also known as FraG [19], and $\mathrm{FraC}$ and FraD $[20,21]$, which are located at the cell poles in the intercellular septa $[18,21]$. Knock-out mutants of sepJ make short filaments (the filament fragmentation phenotype) and are arrested in heterocyst differentiation showing a Fox ${ }^{-}$phenotype (i.e., they are unable to grow fixing $\mathrm{N}_{2}$ under oxic conditions) $[18,19]$. Inactivation of sepJ also results in a decreased number of nanopores [7], whereas overexpression of SepJ results in an increased number of nanopores [22]. Recent work has linked the filament fragmentation phenotype of sepJ mutants to the cell-wall AmiC amidases that drill the nanopores [16]. Thus, filament fragmentation is significantly alleviated in a sepJ amiC1 double mutant as compared to the sepJ mutant [23] This observation suggests that filament fragmentation in the sepJ mutants largely results from the activity of AmiC1, which could be deregulated in the absence of SepJ. Knockout sepJ mutants are additionally impaired in the intercellular transfer of fluorescent markers, mainly calcein [7, 9, 24]. Although fraC and fraD mutants are also impaired in calcein transfer, this effect could result, at least in part, from the observed delocalization of SepJ in the fraC and fraD mutants [21]. On the other hand, overexpression of SepJ specifically increases calcein transfer from vegetative cells to heterocysts [22]. Overall, we consider calcein the best available fluorescent marker to study SepJ-related intercellular transfer in Anabaena. Nonetheless, calcein (a fluorescein complex) is chemically different to possible physiological substrates transferred through SepJ-related septal junctions such as the peptidic PatS morphogen [22, 25]. Therefore, calcein transfer may reflect only partially the transfer properties of SepJ-related septal junctions.

SepJ from heterocyst-forming cyanobacteria contains four differentiated domains (Fig. 1A; discussed in [1]): (i) a conserved $\mathrm{N}$-terminal sequence of 26 amino acids; (ii) a coiled-coil domain (residues 28 to 207 of Anabaena SepJ); (iii) a central linker domain (residues 208 to 411); and (iv) an integral membrane or permease domain (residues 412 to 751). The integral membrane domain is predicted to bear 9,10 or 11 transmembrane segments (TMSs). Because the $C$ terminus of SepJ is most likely cytoplasmic, and because there is evidence for a periplasmic location of the $\mathrm{N}$-terminal extra-membrane section of the protein $[18,26$ 28], we favor a 9- or 11-TMS model for Anabaena SepJ. The last eight TMSs constitute subdomain IM2 [1] that is topologically conserved in available SepJ sequences (see Fig. S1) and shows similarity to proteins in the Drug/Metabolite Transporter (DMT) Superfamily (TCDB number 2.A.7; http://tcdb.org/) [29].

As mentioned above, prior studies have shown a highly pleiotropic phenotype of knock-out sepJ mutants, with effects ranging from filament fragmentation to hampering

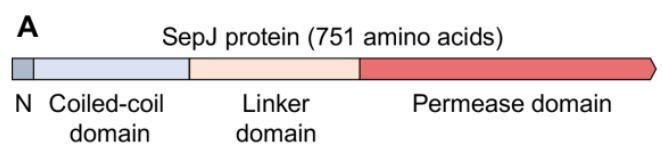

B

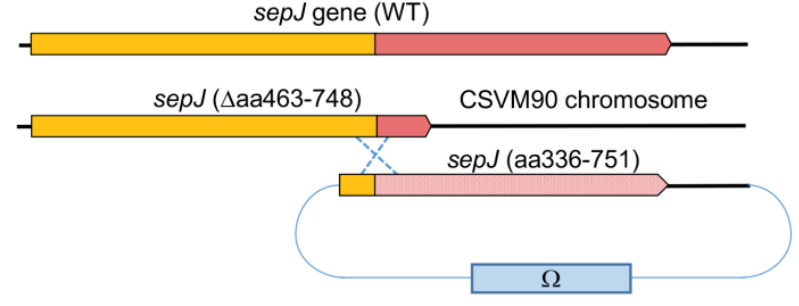

FIGURE 1: The SepJ protein and the sepJ gene from Anabaena. (A) Schematic showing the conserved domains of SepJ. (B) Schematic of the genetic strategy used to re-construct the sepJ gene using CSVM90 as parental strain.

heterocyst differentiation $[18,19]$. The study of Anabaena strains producing SepJ proteins with specific domains deleted has shown an important role of the coiled-coil domain in filament integrity and intercellular molecular exchange, both required for diazotrophy, as well as a general structural role of the permease domain [24]. Additionally, the study of SepJ chimeras has shown a specific role of the permease domain of SepJ from heterocyst-forming cyanobacteria providing functions required for diazotrophy [24]. To gain insight on the permease domain, and hence on SepJ, here we created and investigated a number of mutants altered in the topologically conserved region of the permease (subdomain IM2) or in sequences adjacent to it.

\section{RESULTS}

\section{Experimental design}

The sepJ gene (ORF alr2338) consists of 2,256 bp including its stop codon and occupies positions 2,818,434 to 2,820,689 of the Anabaena chromosome [30]. We constructed strain CSVM90 that bears a sepJ gene with a deletion from bp 1,387 to bp 2,244, and in which the 286 codons deleted are substituted by three codons encoding Asn-Ser-Asn. This sepJ gene encodes a SepJ protein that contains the conserved $\mathrm{N}$-terminal sequence, the coiledcoil domain, the linker domain and only the first predicted transmembrane segment of the permease domain (Fig. S2). Strain CSVM90 exhibited the filament fragmentation phenotype characteristic of sepJ null mutants, formed a number of septal peptidoglycan nanopores similar to that of its $\Delta$ sepJ parental strain CSVM34, and did not produce heterocysts or nitrogenase activity being therefore Fox ${ }^{-}$(see below). We used strain CSVM90 as recipient of constructs containing a sepJ fragment from bp 1009 to the end of the gene that bore a number of different mutations or deletions. This sepJ fragment overlapped the sepJ gene resident in strain CSVM90 by $379 \mathrm{bp}$, allowing integration of the construct by a single recombination event with the effect of reconstructing a sepJ gene with the desired mutation (Fig. 1B). Anabaena clones bearing these constructs were 


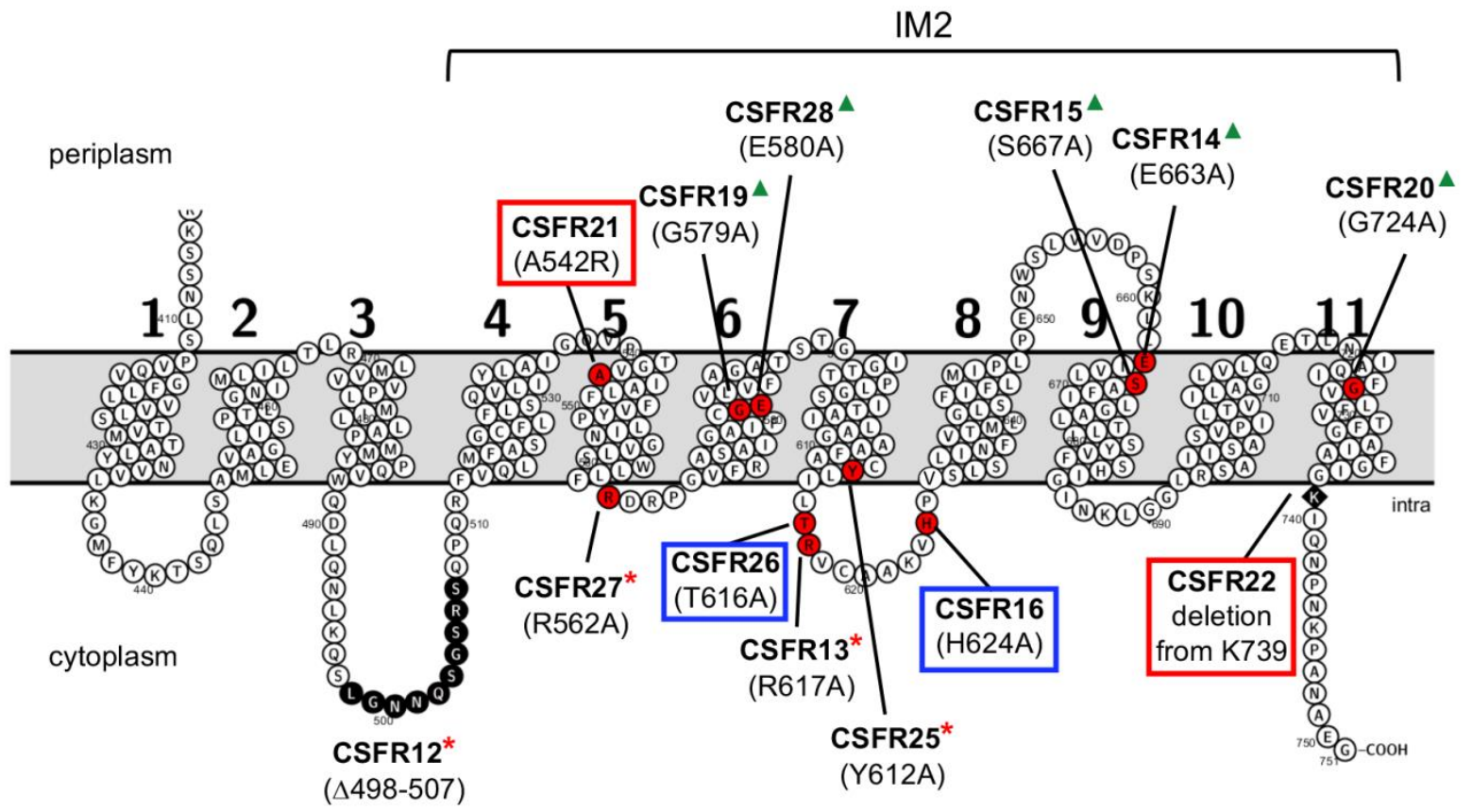

FIGURE 2: Schematic of the permease domain of SepJ from Anabaena sp. PCC 7120 indicating the mutations introduced in this work. Transmembrane segments are numbered 1 to 11 according to the prediction of the TMHMM program. The last eight TMSs are strongly conserved in SepJ proteins constituting subdomain IM2 (see Fig. S1). Because there is strong evidence for a cytoplasmic C-terminus [18, 27], the showed topology is very likely to be correct for subdomain IM2. Red circles, individual amino acids mutated; black circles, residues deleted in strain CSFR12; black rhomboid, residue at which a C-terminal deletion started. Group 1 mutations are framed in red; group 2 mutations are framed in blue; group 3 mutations are indicated by red asterisks; group 4 mutations are indicated by green triangles.

recovered by selection for resistance to $\mathrm{Sm}$ (spectinomycin dihydrochloride pentahydrate) and $\mathrm{Sp}$ (streptomycin sulfate) encoded by the $\Omega$ cassette present in the transferred plasmid (Fig. 1B).

In the region of the last eight TMSs of SepJ from heteterocyst-forming cyanobacteria (subdomain IM2), about $1 / 3$ of the amino acid residues are strongly conserved (Fig. S3). We chose for mutation some residues located in predicted cytoplasmic loops or TMSs, and we also prepared two deletions that affected this region of the protein or adjacent sequences (Fig. 2). We first prepared Anabaena strains producing SepJ with the following point mutations: $A_{542} R$ (strain CSFR21), $R_{562} A$ (strain CSFR27), $G_{579} A$ (strain CSFR19), $E_{580} A$ (strain CSFR28), $Y_{612} A$ (strain CSFR25), $T_{616} A$ (strain CSFR26), $R_{617} A$ (strain CSFR13), $H_{624} A$ (strain CSFR16), $E_{663} A$ (strain CSFR14), $S_{667} A$ (strain CSFR15), and $\mathrm{G}_{724} \mathrm{~A}$ (strain CSFR20). We then prepared Anabaena strain CSFR12 that produces a SepJ protein with a deletion of amino acid residues 498 to 507 (SepJ $\left.\mathrm{S}_{\Delta 98-507}\right)$, which are part of a predicted extra-membrane loop of the protein that likely resides in the cytoplasm (Fig. 2) and is found only in SepJ from heterocyst-forming cyanobacteria. We finally prepared a strain, CSFR22, that bears a deletion of the 13 C-terminal amino acids of the protein $\left(\operatorname{SepJ}_{\Delta 739-751}\right)$, which is a predicted cytoplasmic tail (Fig. 2). A strain, CSFR11, resulting from complementation of CSVM90 with a sepJ fragment of the wild-type sequence from bp 1009 to the end of the gene was constructed to be used as a positive control.

The test Anabaena strains bearing the different mutated sepJ genes were studied along with four controls: wildtype Anabaena, strain CSVM34 ( $\Delta$ sepJ), strain CSVM90 $\left(\operatorname{SepJ}_{\triangle 463-748}\right)$, and strain CSFR11 (SepJ). They were characterized for the production and subcellular localization of SepJ, the capability to make long filaments, diazotrophy (diazotrophic growth, nitrogenase activity, heterocyst formation), and intercellular transfer of calcein. In some strains, the septal peptidoglycan nanopores were also studied. The results are presented as groups of mutants clustered according to their phenotypes.

\section{Group 1 mutants}

Knock-out mutants of sepJ make short filaments when grown in media containing combined nitrogen and fragment further upon incubation without combined nitrogen $[18,19,24]$. When grown in BG11 medium (containing nitrate as a nitrogen source), all but three of the 13 test mutants analyzed in this work formed a substantial fraction of long filaments (Fig. 3A). Strains CSFR21 and CSFR22 not only made a low proportion of long filaments in BG11 medium but also fragmented extensively in $\mathrm{BG}_{1} 1_{0}$ medium that lacks any source of combined nitrogen (Fig. 3B). These strains constitute phenotypic group 1 . 
A

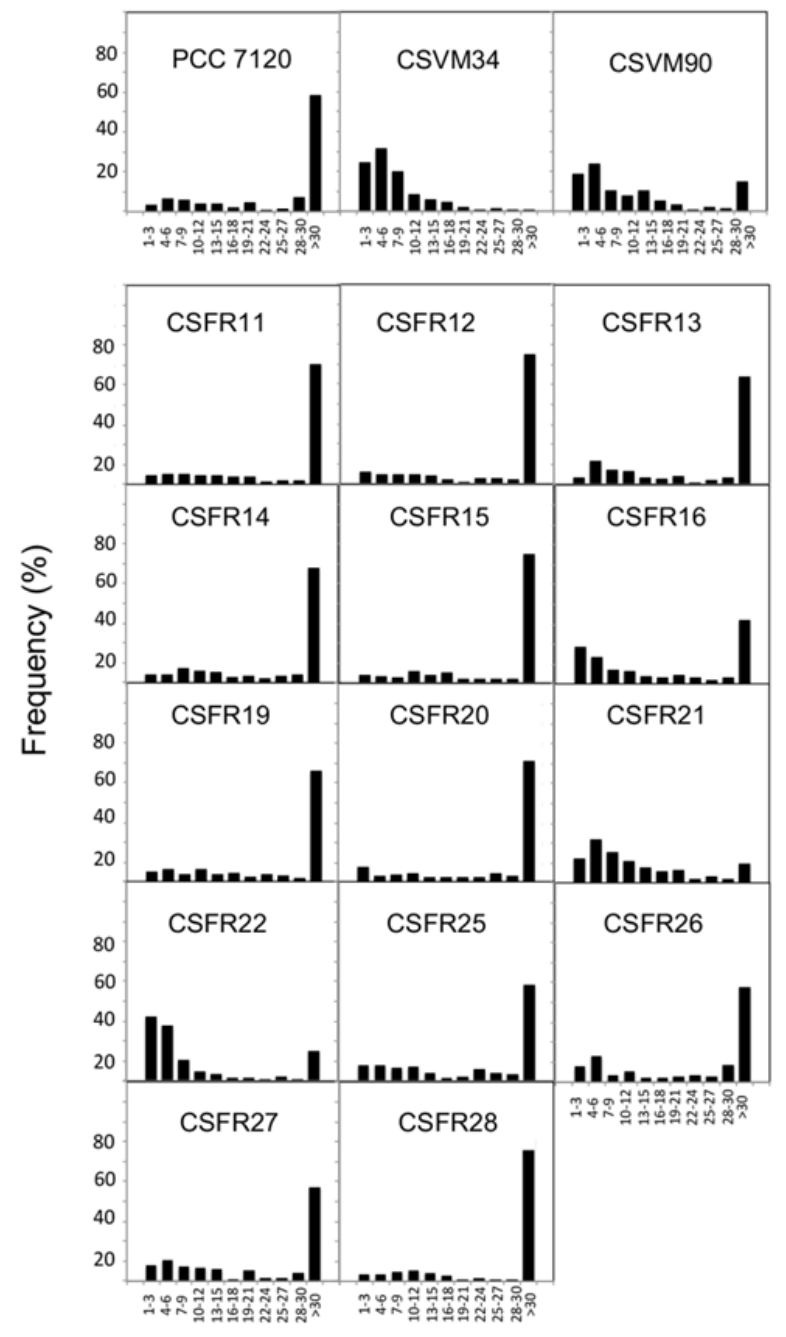

Number of cells per filament
B
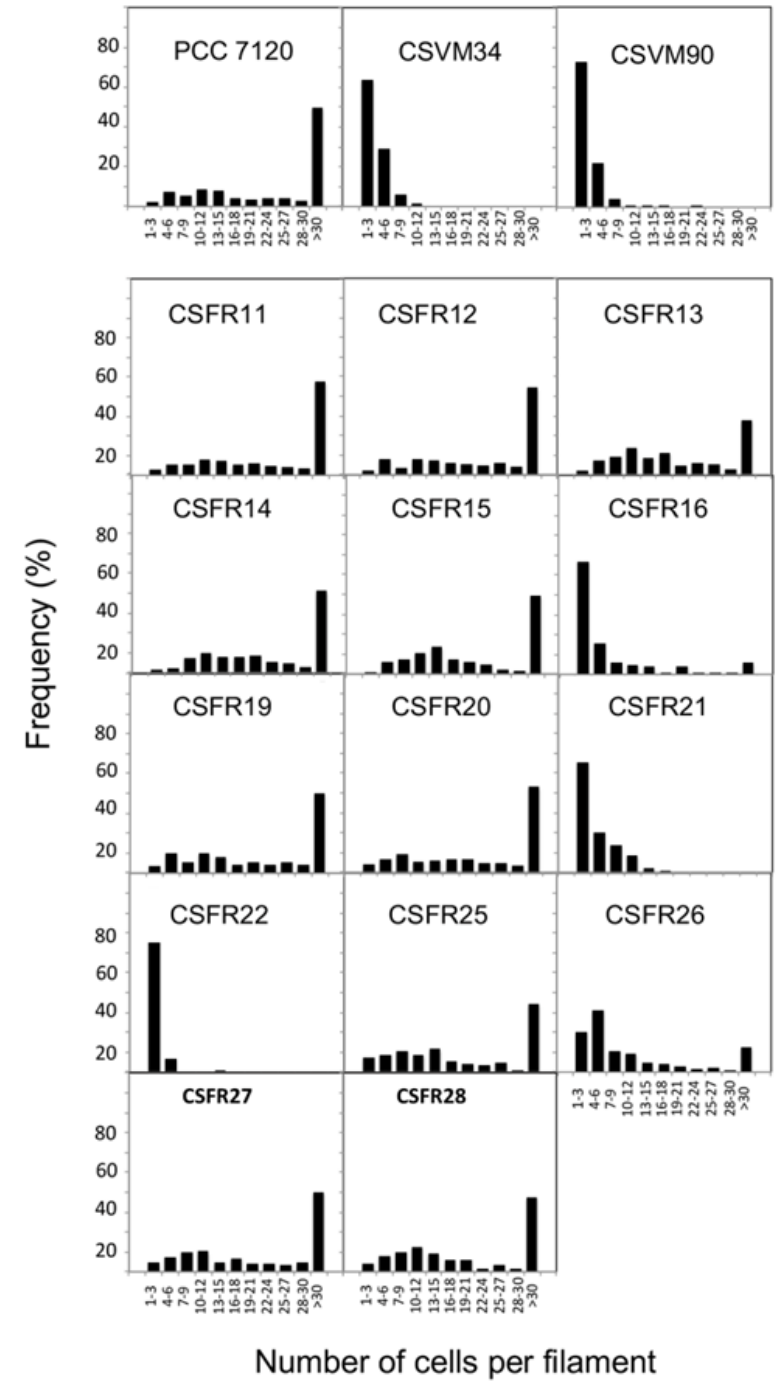

Number of cells per filament

FIGURE 3: Filament length in Anabaena (PCC 7120) and sepJ mutant strains grown in BG11 medium (A) or grown in BG11 medium and incubated $48 \mathrm{~h}$ in $\mathrm{BG}_{1} 1_{0}$ medium (B).

To assess the production of SepJ in the mutants, we performed immunolocalization of SepJ with antibodies raised against the coiled-coil domain of the protein. In the control strains, SepJ was observed in the intercellular septa of filaments from the wild type and strain CSFR11 (SepJ), was missing from CSVM34 ( $\Delta$ sepJ), and was observed scattered in the cells (only sporadically in the septa but frequently peripheral) in strain CSVM90 (Fig. 4). SepJ could be detected in the 13 test strains, indicating production of the protein (Fig. 4). In strains CSFR21 and CSFR22, however, although SepJ was observed located in some septa, it was also observed disperse in the cells.

As explained in the introduction, SepJ-related intercellular molecular transfer can be tested with calcein. We studied transfer of calcein between vegetative cells in filaments grown in BG11 medium, in which all the mutant strains made filaments of a size sufficient to carry out FRAP analysis. Strain CSFR22 was significantly impaired in calcein transfer (Table 1), and strain CSFR21 showed slower transfer than the control strain CSFR11, although the difference could not be defined as statistically significant (Student's $t$ test $p=0.068$ ). Strains CSFR21 and CSFR22 did not express nitrogenase activity, did not form heterocysts and, consistently, showed a Fox ${ }^{-}$phenotype (Table 1, Fig. 5). Hence, phenotypic group 1 mutants produce a SepJ protein that cannot fulfill its roles in filamentation and heterocyst differentiation. 


\section{Group 2 mutants}

Strains CSFR16 and CSFR26 formed long filaments in BG11 medium but, especially in the case of CSFR16, they were observed at a lower frequency than in the positive controls

\section{Controls}

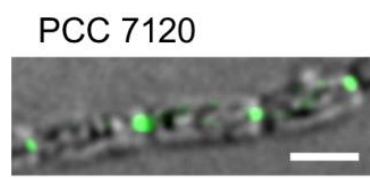

CSVM34
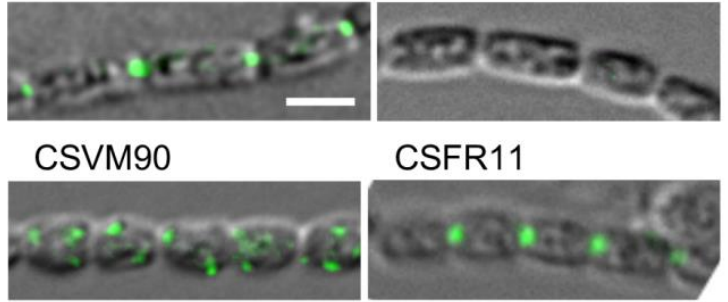

CSFR11

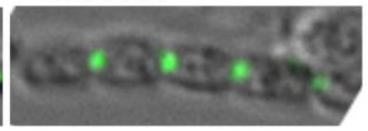

\section{Group 1}

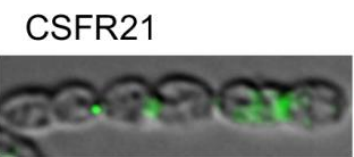

CSFR22

\section{Group 2}

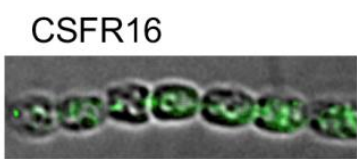

\section{CSFR26}

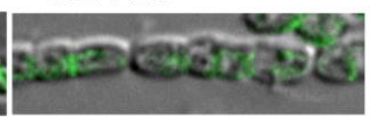

\section{Group 3}

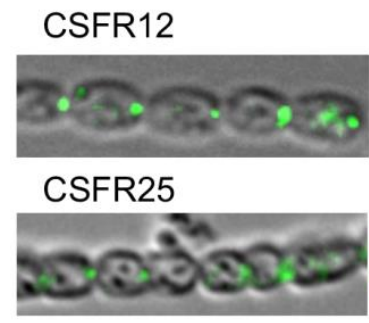

\section{CSFR13}

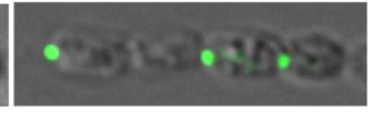

\section{CSFR27}

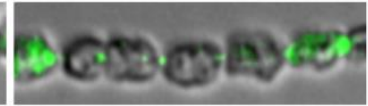

\section{Group 4}

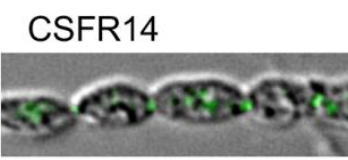

CSFR15

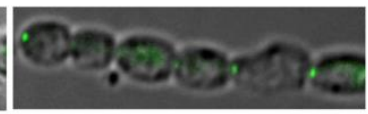

CSFR19

CSFR20
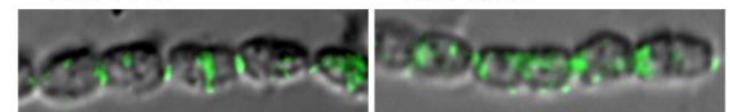

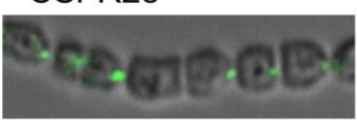

FIGURE 4: Immunolocalization of SepJ in filaments of the indicated strains grown in BG11 medium. Immunolocalization was performed as described in Materials and Methods with antibodies raised against the coiled-coil domain of SepJ. The mutants are organized according to the phenotypic groups described in the text. Scale bar, $3 \mu \mathrm{m}$.

(Fig. 3A) and fragmented appreciably upon incubation in BG11 0 medium (Fig. 3B), defining phenotypic group 2. In these strains, SepJ was hardly associated with the intercellular septa (Fig. 4) and calcein transfer was impaired (Table 1). Whereas strain CSFR26 produced heterocysts and nitrogenase activity at appreciable levels, strain CSFR16 produced a low percentage of heterocysts and low nitrogenase activity (Table 1). Consistently, whereas CSFR26 showed substantial diazotrophic growth, CSFR16 showed only weak diazotrophic growth (a weak $\mathrm{Fox}^{+}$phenotype; Fig. 5). Therefore, the SepJ protein in phenotypic group 2 mutants provides filamentation function in BG11 medium and allows heterocyst differentiation, but fails to keep normal filamentation under nitrogen deprivation.

\section{Group 3 mutants}

The rest of the 13 test mutants (group 3 and group 4 strains in Table 1) produced a high proportion of long filaments in both BG11 and BG11 0 media (Fig. 3), formed heterocysts, exhibited unimpaired nitrogenase activity (except strain CSFR14) and were Fox ${ }^{+}$(Fig. 5). Four of them, strains CSFR12, CSFR13, CSFR25 and CSFR27, were significantly impaired in calcein transfer (Table 1); based on this, they were defined as phenotypic group 3. SepJ was well located at the intercellular septa in CSFR12 and CSFR13 and was also observed associated with the septa in CSFR25 and CSFR27, although in the latter some label was also observed out of the septa (Fig. 4). Because strains CSFR12 and CSFR13 were impaired in calcein transfer but showed SepJ well localized, nanopore formation was studied in strain CSFR12 (Fig. 6). The number of nanopores in strain CSFR12 was smaller than in the positive control strain CSFR11, although not as small as in strain CSVM90 (Fig. 6). The size of the nanopores in strain CSFR12 was however similar to that in the control strain CSFR11 (Fig. 6). As a reference, the number and size (diameter in $\mathrm{nm}$ ) of nanopores is about $52.3 \pm 6.2$ nanopores per septal disk and $18.5 \pm 3.5$ $\mathrm{nm}$ in wild-type Anabaena [22], and $14.0 \pm 7.6$ nanopores per septal disk and $16.8 \pm 5.0 \mathrm{~nm}$ in the $\Delta$ sepJ strain CSVM34 [7]. In summary, strain CSFR12 shows a decreased rate of calcein transfer ( $37 \%$ and $34 \%$ compared to control strain CSFR11 and the wild type, respectively) and a reduced number of nanopores per septal disk (59\% and 50\% compared to the control strain CSFR11 and the wild type, respectively).

\section{Group 4 mutants}

In strains CSFR14, CSFR15, CSFR19, CSFR20 and CSFR28, SepJ was observed associated with the intercellular septa, although in CSFR20 some delocalized signal was also observed (Fig. 4) (SepJ immunofluorescence signal in the middle of the cell, as observed in CSFR19, is frequently seen also in the wild type, where it is associated with the divisome at the start of cell division [27]). These strains showed also normal or not significantly altered activity of calcein transfer (Table 1). Nanopores were studied in strains CSFR14 and CSFR15 and found to be present in a similar number as in the control strain CSFR11 (Fig. 6). In 
TABLE 1. Calcein transfer, Fox phenotype, nitrogenase activity and heterocysts in sepJ mutant strains.

\begin{tabular}{|c|c|c|c|c|c|}
\hline $\begin{array}{l}\text { Strain } \\
\text { (Genotype or SepJ protein) }\end{array}$ & Calcein transfer ${ }^{\mathrm{a}}$ & $\begin{array}{l}\text { Fox pheno- } \\
\text { type }^{b}\end{array}$ & $\begin{array}{l}\text { Nitrogenase } \\
\text { activity }^{c}\end{array}$ & $\begin{array}{c}24 \mathrm{~h} \\
\% \text { Hets }^{d}\end{array}$ & $\begin{array}{c}48 \mathrm{~h} \\
\% \text { Hets }^{d}\end{array}$ \\
\hline \multicolumn{6}{|l|}{ Controls } \\
\hline PCC 7120 (WT) & $0.067 \pm 0.023(6)$ & + & $4.67 \pm 0.53$ & $7.41 \pm 0.47$ & $8.17 \pm 0.18$ \\
\hline CSVM34 ( $\Delta$ sepJ) & $0.016 \pm 0.006(8)^{* *}$ & - & $0.00 \pm 0.00 * *$ & 0 & 0 \\
\hline $\operatorname{CSVM} 90\left(\operatorname{SepJ}_{\Delta 463-748}\right)$ & $0.020 \pm 0.008(10)^{* *}$ & - & $0.00 \pm 0.00 * *$ & 0 & 0 \\
\hline CSFR11 (SepJ) & $0.062 \pm 0.007(14)$ & + & $5.26 \pm 1.70$ & $7.88 \pm 0.48$ & $9.02 \pm 0.07$ \\
\hline \multicolumn{6}{|l|}{ Group 1} \\
\hline $\operatorname{CSFR} 21\left(\operatorname{SepJ}_{\mathrm{A542R}}\right)$ & $0.043 \pm 0.006(21)$ & - & $0.00 \pm 0.00 * *$ & 0 & 0 \\
\hline $\operatorname{CSFR22}\left(\operatorname{SepJ}_{\Delta 739-751}\right)$ & $0.038 \pm 0.008(20)^{*}$ & - & $0.00 \pm 0.00 * *$ & 0 & 0 \\
\hline \multicolumn{6}{|l|}{ Group 2} \\
\hline $\operatorname{CSFR16}_{\left(\text {SepJ }_{\mathrm{H} 624 \mathrm{~A}}\right)}$ & $0.028 \pm 0.0012(9)^{*}$ & {$[+]$} & $1.44 \pm 0.62 *$ & $2.14 \pm 0.78^{* *}$ & $2.36 \pm 1.49$ \\
\hline CSFR26 (SepJ J616A & $0.025 \pm 0.009(18)^{* *}$ & + & $6.16 \pm 2.80$ & $3.07 \pm 2.29 *$ & $7.77 \pm 2.00$ \\
\hline \multicolumn{6}{|l|}{ Group 3} \\
\hline $\operatorname{CSFR12}\left(\operatorname{SepJ}_{\triangle 498-507}\right)$ & $0.023 \pm 0.008(15)^{* *}$ & + & $4.75 \pm 1.97$ & $7.26 \pm 0.53$ & $8.21 \pm 1.29$ \\
\hline $\operatorname{CSFR13}\left(\operatorname{SepJ}_{\mathrm{R617A}}\right)$ & $0.027 \pm 0.008(18)^{* *}$ & + & $4.89 \pm 1.41$ & $6.64 \pm 2.94$ & $8.08 \pm 0.86$ \\
\hline CSFR25 (SepJ $\left.\mathrm{Y}_{\mathrm{Y} 12 \mathrm{~A}}\right)$ & $0.028 \pm 0.008(11)^{* *}$ & + & $2.46 \pm 1.35$ & $5.43 \pm 0.92 *$ & $8.27 \pm 0.38$ \\
\hline CSFR27 (SepJ R562A $\left._{1}\right)$ & $0.029 \pm 0.007(20)^{* *}$ & + & $5.09 \pm 1.91$ & $7.08 \pm 1.51$ & $8.65 \pm 0.80$ \\
\hline \multicolumn{6}{|l|}{ Group 4} \\
\hline CSFR14 (SepJ $\left.\mathrm{E} 663 \mathrm{~A}_{\mathrm{A}}\right)$ & $0.060 \pm 0.011(14)$ & + & $2.02 \pm 0.99 *$ & $8.31 \pm 0.85$ & $9.96 \pm 0.67$ \\
\hline CSFR15 (SepJ $\left.\mathrm{S}_{\mathrm{S667A}}\right)$ & $0.077 \pm 0.016(12)$ & + & $5.35 \pm 1.65$ & $6.00 \pm 2.50$ & $8.09 \pm 1.97$ \\
\hline CSFR19 (SepJ G579A $\left._{1}\right)$ & $0.052 \pm 0.017(8)$ & + & $3.90 \pm 0.96$ & $8.01 \pm 1.45$ & $8.86 \pm 0.96$ \\
\hline $\operatorname{CSFR} 20\left(\operatorname{SepJ}_{\mathrm{G724A}}\right)$ & $0.060 \pm 0.008(19)$ & + & $3.17 \pm 1.63$ & $8.61 \pm 0.35$ & $9.29 \pm 0.53$ \\
\hline CSFR28 (SepJ $\left.\mathrm{E}_{\mathrm{E} 80 \mathrm{~A}}\right)$ & $0.046 \pm 0.006(12)$ & + & $7.37 \pm 3.30$ & $6.69 \pm 1.04$ & $8.68 \pm 1.31$ \\
\hline
\end{tabular}

${ }^{a}$ Intercellular transfer of calcein was determined by FRAP analysis performed with filaments that had been grown in BG11 medium (supplemented with antibiotics for the CSFR mutants). Data presented as the recovery constant $R\left(\mathrm{~s}^{-1}\right)$, mean \pm SEM of $12-29$ filaments from 3 independent cultures. The difference between each strain and the complemented CSFR11 mutant (used for reference) was assessed with the Student's $t$ test $\left(*, p<0.05 ;{ }^{* *}, p<0.01\right)$.

${ }^{\mathrm{b}}$ Fox phenotype (growth on solid BG11 0 medium as shown in Fig. 5): +, positive; -, negative; [+], weak positive.

${ }^{\mathrm{c}}$ Nitrogenase activity was determined as acetylene reduction in assays performed under oxic conditions with filaments that had been grown in BG11 medium (with antibiotics for the CSFR mutants) and incubated in BG11 o medium (without antibiotics) for $48 \mathrm{~h}$. Data presented as $\mu \mathrm{mol}(\mathrm{mg} \mathrm{Chl})^{-1} \mathrm{~h}^{-1}$, mean \pm SEM of 2 (for strains which do not develop heterocysts), 3 or 4 (for CSFR11) independent cultures. The significance of the difference between mutant and strain CSFR11 assessed with the Student's test $(*, p \leq 0.05 ; * *, p<0.01)$.

${ }^{d}$ Heterocysts were visualized in filaments grown in BG11 medium (with antibiotics for the CSFR mutants) and incubated in BG11 0 medium without antibiotics for 24 or $48 \mathrm{~h}$, as indicated. The percentage of heterocysts was determined for each of three independent cultures. When present, at least 100 heterocysts from each culture were counted. Data are mean $\pm S D(n=3)$. The significance of the difference between each mutant and strain CSFR11 was assessed with the Student's $t$ test $\left({ }^{*}, p \leq 0.05 ;{ }^{* *}, p<0.01\right)$. 

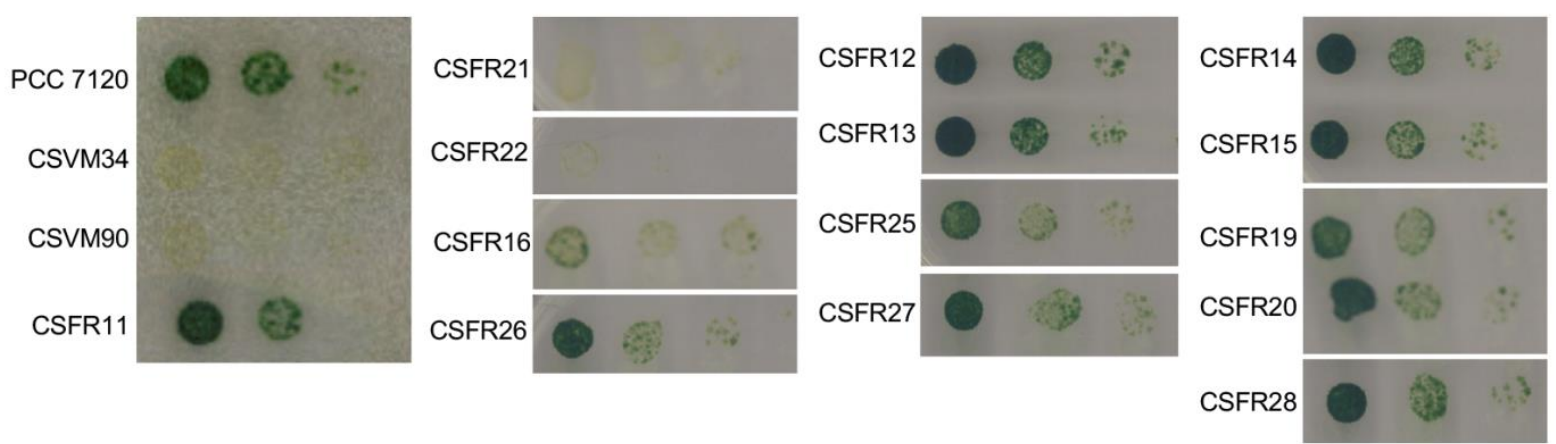

FIGURE 5: Growth test on solid medium of Anabaena and the sepJ mutants. Suspensions of filaments that had been grown in BG11 medium (in the presence of antibiotics for the CSFR mutants) were washed with BG $11_{0}$ medium (lacking any source of combined nitrogen) and resuspended in the same medium. Serial dilutions containing 5, 0.5 and $0.05 \mathrm{ng}$ of Chl were spotted on solid BG11 0 medium, incubated under growth conditions and photographed after 10 days.

summary, the results with group 4 strains identify SepJ mutations that give a phenotype similar to the wild-type phenotype (only strain CSFR14 was somewhat impaired in nitrogenase activity; Table 1).

\section{DISCUSSION}

As an important contributor to the formation of septal junctions in Anabaena, the SepJ protein is needed to make long filaments in both media containing and media lacking a source of combined nitrogen, although its effect is most stringent in the absence of combined nitrogen [18, 19]. SepJ is also required for Anabaena to make a normal number of septal peptidoglycan nanopores and is involved in intercellular molecular exchange as shown with fluorescent markers, especially calcein [7, 9, 24]. Additionally, knockout mutants of sepJ are arrested in heterocyst differentiation, which may be related to a function of SepJ in transfer of regulators of heterocyst differentiation [22, 25, 31]. Our current model is that SepJ forms complexes [28] that constitute or contribute to form one type of septal junctions, which make conduits through which intercellular molecular exchange can take place. To further investigate the role of SepJ in septal junctions, we studied Anabaena strains that produce SepJ with different deletions or point mutations in subdomain IM2 or adjacent sequences of its permease domain (Fig. 2).

Anabaena strain CSVM90 produces a SepJ protein containing only the first predicted TMS (Fig. S2). This protein does not localize to the intercellular septa, but its frequent peripheral localization suggests that it may be integrated into the cytoplasmic membrane (Fig. 4). We have previously reported Anabaena strain CSVM36 that produces a SepJ protein that lacks TMSs 8 and 9 but is nevertheless incorporated into the cytoplasmic membrane at a low level [24]. Strain CSVM90 produces a low number of septal peptidoglycan nanopores (Fig. 6) and shows a rate of intercellular calcein transfer (Table 1 ) similar to its $\Delta$ sepJ parental strain CSVM34. Hence, the SepJ protein produced in strain CSVM90 is not functional. When a wild-type sepJ gene was reconstituted using CSVM90 as a parental strain, a strain (CSFR11) exhibiting a wild-type phenotype was obtained, but when sepJ versions with specific mutations were introduced, some strains with altered phenotypes and some with a wild-type phenotype were obtained (summarized in Table 2). The latter are those of phenotypic group 4, which therefore include mutations that hardly affect SepJ function. All of the group 4 mutations change amino acids located in TMSs. In three of these mutants Ala substitutes for a small amino acid (CSFR15, $\mathrm{S}_{667} \mathrm{~A}$; CSFR19, $\mathrm{G}_{579} \mathrm{~A}$; CSFR20, $\mathrm{G}_{724} \mathrm{~A}$ ), and in two mutants Ala substitutes for Glu (CSFR14, $E_{663} A$; CSFR28, $E_{580} A$ ). Whereas $E_{580}$ is replaced by $G \ln$ in some cyanobacteria (Fig. S3), indicating that the negative charge of Glu is not essential at this position, $E_{663}$ is invariant. The mutant bearing the $\mathrm{E}_{663} \mathrm{~A}$ mutation, strain CSFR14, showed somewhat impaired nitrogenase activity (Table 1), making this mutant of interest for further research.

Group 1 mutants are impaired in filamentation and heterocyst differentiation, and therefore they identify two mutations $\left(A_{542} R\right.$ in CSFR21; SepJ ${ }_{\Delta 739-751}$ in CSFR22) that impede the reconstitution of a SepJ protein with any functionality. Group 2 mutants produce long filaments in the presence of combined nitrogen that fragment after nitrogen step-down, and they form heterocysts in spite of being deficient in calcein transfer. These results suggest that making long filaments (in medium containing combined nitrogen) is needed to produce heterocysts upon nitrogen deprivation. In group 1 mutants, incorporation of a bulky and positively charged amino acid (Arg) at the position of $A_{542}$ in TMS 5 (CSFR21) or deletion of the C-terminal cytoplasmic tail (CSFR22) impede SepJ function. In group 2 mutants, the amino acids changed $\left(\mathrm{H}_{624} \mathrm{~A}\right.$ in CSFR16; $\mathrm{T}_{616} \mathrm{~A}$ in CSFR26) are located in the same predicted cytoplasmic loop (between TMSs 7 and 8) of the SepJ permease (Fig. 2), and their substitution by Ala residues appear to partially hamper the contribution of SepJ to filament integrity, with a stringent effect upon nitrogen deprivation. As mentioned in the Introduction, filament fragmentation in Anabaena likely results, to a large extent, from the deregulated activi- 


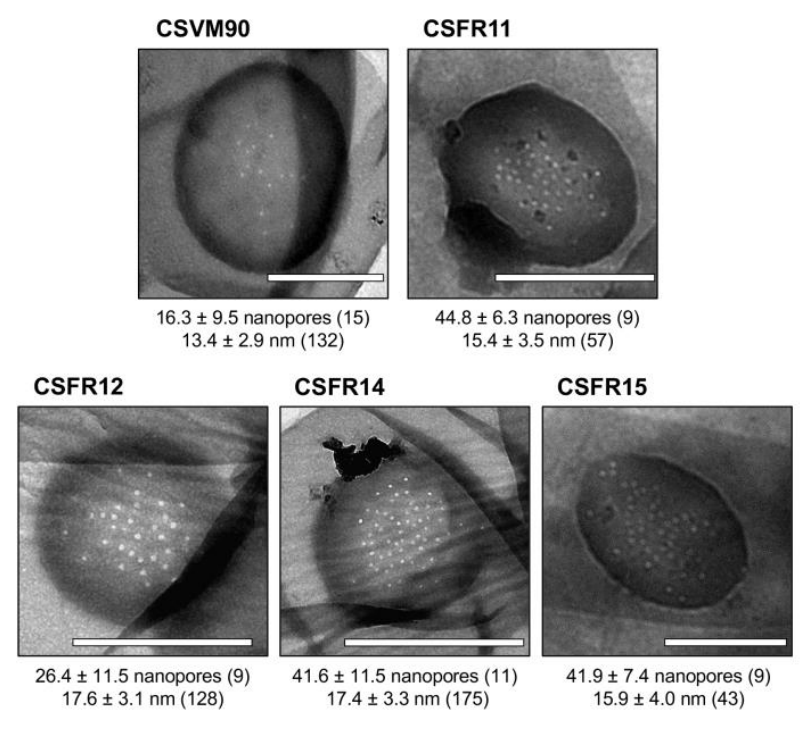

FIGURE 6: Nanopores in septal peptidoglycan disks of the indicated Anabaena strains. Quantification of nanopores (mean \pm SD; number of disks quantified in parenthesis) and nanopore diameter (mean $\pm \mathrm{SD}$; number of nanopores measured in parenthesis) are indicated below each micrograph. Scale bars, $1 \mu \mathrm{m}$.

ty of the cell-wall amidase AmiC1 [23]. The mutated SepJ proteins of strains in group 1 and group 2 may not form normal SepJ complexes (group 1) or may form weak complexes (group 2), ultimately affecting the regulation of AmiC1. In Anabaena, the LytM factor Alr3353 has been identified as a regulator of AmiC1 [32], but how SepJ influences AmiC1 or Alr3353 activity is unknown, and additional partners may be involved in this regulatory system. For example, we have recently shown that inactivation of $\mathrm{GlsC}$, a nucleotide-binding protein of an $A B C$ glucoside transporter, impairs both SepJ localization and nanopore formation [33]

Group 3 mutants produce long filaments in the presence and absence of combined nitrogen, form heterocysts and can grow diazotrophically, but they are impaired in the intercellular transfer of calcein. A group 3 strain, CSFR12, in which nanopores were visualized, produced a low number of nanopores, consistent with slow calcein transfer. Hence, group 3 strains appear to produce SepJ proteins that form septal junctions that contribute to filament integrity and provide the intercellular transfer function needed for diazotrophic growth, but fail to provide the full function of intercellular transfer that can be traced with calcein. We have previously described that an Anabaena mutant that produces a SepJ protein lacking its linker domain (strain CSVM85) shows normal diazotrophic growth while being impaired in calcein transfer [24]. Therefore, it appears that diazotrophic growth and calcein transfer do not strictly correlate. It is possible that the intercellular transfer of nutrients that takes place in the Anabaena filament is more related to FraCD than to SepJ [7], whereas SepJ may be involved in the intercellular transfer of regulators [22, $25,31]$. A more detailed study would be necessary to de- termine whether the group 3 mutants have any regulatory alteration. The mutations in the SepJ protein of the four group 3 mutants are placed in predicted cytoplasmic loops (CSFR12, $\Delta 498-507$; CSFR13, $\mathrm{R}_{617} \mathrm{~A}$; CSFR27, $\mathrm{R}_{562} \mathrm{~A}$ ) or close to the cytoplasmic face of the membrane in a TMS (CSFR25, $\mathrm{Y}_{612} \mathrm{~A}$ ) (Fig. 2).

The effects of group 3 mutations could suggest that the SepJ permease domain mediates some type of transport. However, the SepJ protein is prone to self-interactions and appears to form complexes in vivo $[27,28]$. This raises the question whether each SepJ subunit acts independently as a transporter or, alternatively, different subunits of SepJ make a complex that forms a conduit through which molecular transfer takes place. A model for these conduits could be the structures -connexons- formed by the connexins in metazoan gap junctions, which allow diffusion of small ions and metabolites between cells [34, 35]. Formation of such a conduit by SepJ is consistent with intercellular molecular transfer by diffusion as observed in Anabaena $[7,9,11]$. Nonetheless, interactions of the transferred molecules with the conduits are possible, especially in the case of calcein [36]. Interestingly, connexin mutants that show altered permeability for some particular metabolites have been described (see, e.g., [37-39]). Some of the mutations that we have investigated impair calcein transfer without affecting filamentation -those in group 3 strains- or affecting filamentation only partially -those in group 2 strains-. All these mutations involve amino acids located in the cytoplasmic face of the permease (Fig. 2), making it possible that the impairment in calcein transfer results from an alteration in the selectivity of access of the fluorescent marker to the conduits formed by the SepJrelated septal junctions.

As mentioned earlier, the phenotype of knock-out sepJ mutants is very pleiotropic, with effects on intercellular communication, filament integrity and heterocyst differentiation [9, 18, 19, 24], implying multiple roles of SepJ in Anabaena. The varied phenotypic alterations associated with the mutations in the permease domain of SepJ described in this work, ranging from alterations in filament integrity and heterocyst formation to partial alterations in the intercellular transfer of the fluorescent marker calcein, are consistent with such multiple roles of SepJ in maintaining multicellularity in Anabaena.

\section{MATERIALS AND METHODS}

\section{Strains and growth conditions}

Anabaena sp. strain PCC 7120 (also known as Nostoc sp.) was grown in $\mathrm{BG} 11$ (containing $\mathrm{NaNO}_{3}$ ), modified to contain ferric citrate instead of ferric ammonium citrate [40], or $\mathrm{BG}^{1} 1_{0}$ (free of combined nitrogen) medium at $30^{\circ} \mathrm{C}$ in the light (25-50 $\mathrm{mmol}$ photons $\mathrm{m}^{-2} \mathrm{~s}^{-1}$ ), in shaken liquid cultures or in medium solidified with $1 \%$ Difco agar. For strains containing the $\Omega$ cassette, the BG11 medium was supplemented with streptomycin sulfate $(\mathrm{Sp})$ and spectinomycin dihydrochloride pentahydrate $(\mathrm{Sm})$ each at $2 \mu \mathrm{g} \mathrm{ml}^{-1}$ for liquid media and $5 \mu \mathrm{g}$ $\mathrm{ml}^{-1}$ for solid media. 
TABLE 2. Summary of phenotypic characteristics of the engineered sepJ mutants.

\begin{tabular}{|c|c|c|c|c|c|c|}
\hline \multirow[t]{2}{*}{ Phenotypic group } & \multicolumn{2}{|c|}{ Mutant strains } & \multicolumn{2}{|c|}{ Filamentation $^{\mathrm{a}}$} & \multirow{2}{*}{$\begin{array}{l}\text { Diazotrophic } \\
\text { performance }^{b}\end{array}$} & \multirow{2}{*}{$\begin{array}{l}\text { Calcein } \\
\text { transfer }^{c}\end{array}$} \\
\hline & Name & SepJ protein & BG11 & BG11 $_{0}$ & & \\
\hline Parental strain & CSVM90 & $\Delta_{463-748}$ & - & - & - & $(+)$ \\
\hline \multirow[t]{2}{*}{1} & CSFR21 & $\mathrm{A}_{542} \mathrm{R}$ & - & - & - & $(++)$ \\
\hline & CSFR22 & $\Delta_{739-751}$ & - & - & - & $(++)$ \\
\hline \multirow[t]{2}{*}{2} & CSFR16 & $\mathrm{H}_{624} \mathrm{~A}$ & {$[+]$} & - & {$[+]$} & $(+)$ \\
\hline & CSFR26 & $\mathrm{T}_{616} \mathrm{~A}$ & + & - & + & $(+)$ \\
\hline \multirow[t]{4}{*}{3} & CSFR12 & $\Delta_{498-507}$ & + & + & + & $(+)$ \\
\hline & CSFR13 & $\mathrm{R}_{617} \mathrm{~A}$ & + & + & + & $(+)$ \\
\hline & CSFR25 & $\mathrm{Y}_{612} \mathrm{~A}$ & + & + & + & $(+)$ \\
\hline & CSFR27 & $\mathrm{R}_{562} \mathrm{~A}$ & + & + & + & $(+)$ \\
\hline \multirow[t]{5}{*}{4} & CSFR14 & $\mathrm{E}_{663} \mathrm{~A}$ & + & + & + & +++ \\
\hline & CSFR15 & $\mathrm{S}_{667} \mathrm{~A}$ & + & + & + & +++ \\
\hline & CSFR19 & $\mathrm{G}_{579} \mathrm{~A}$ & + & + & + & +++ \\
\hline & CSFR20 & $\mathrm{G}_{724} \mathrm{~A}$ & + & + & + & +++ \\
\hline & CSFR28 & $\mathrm{E}_{580} \mathrm{~A}$ & + & + & + & +++ \\
\hline Reconstituted wild type & CSFR11 & WT SepJ & + & + & + & +++ \\
\hline
\end{tabular}

${ }^{a}$ Data from Fig. 3: +, normal filament length; [+], intermediate filament length; -, extensive filament fragmentation.

${ }^{b}$ Diazotrophic performance summarizes diazotrophic growth (Fox phenotype, from Fig. 5), nitrogenase activity, and production of heterocysts (from Table 1). +, positive; [+], weak positive; -, negative.

c Calcein transfer is summarized as: +++, normal (not significantly different from the CSFR11 control); (++), defective (61 to $69 \%$ of the CSFR11 control; note that the difference between strains CSFR21 and CSFR11 could not be defined as statistically significant); (+), defective ( 37 to $47 \%$ of the CSFR11 control; $32 \%$ in the case of CSVM90) (see text and Table 1 for details).

\section{Construction of mutant strains}

The DNA sequence of all the plasmids constructed for generation of mutant strains was confirmed by sequencing. For construction of CSVM90, a 5' fragment from the sepJ gene was amplified using oligonucleotide primers alr2338-25 and alr2338-30, and a 3' fragment using primers alr2338-29 and alr2338-34 (oligodeoxynucleotide primers are described in Table S1). Both fragments were digested with EcoRI, ligated, and the resulting product was amplified using primers alr2338-25 and alr2338-34. The PCR product was digested with Spel/Xbal and cloned in Xbal-digested vector pCSRO, which can be mobilized by conjugation and bears an $\mathrm{Sm}^{\mathrm{R}} / \mathrm{Sp}^{\mathrm{R}}$ determinant and the $s a c B$ gene for positive selection [41]. The resulting plasmid, called pCSVM90, was transferred to Anabaena by conjugation, which was performed as described previously [42]. Exconjugants were selected by their resistance to $\mathrm{Sm}$ and $\mathrm{Sp}$ and double recombinants were then selected by their resistance to sucrose. The clone isolated, CSVM90, lacked 286 codons of the permease domain (from bp 1,387 to bp 2,244 of the gene), which were substituted by three codons encoding Asn-Ser-Asn.

For complementation of CSVM90, a part of wild-type sepJ and $385 \mathrm{bp}$ of downstream sequence was amplified by PCR using oligonucleotide primers alr2338-37 and alr2338-38 and cloned in EcoRI-digested pCSV3 [43]. The resulting plasmid, named pCSFR53, was transferred to strain CSVM90 by conju- gation obtaining strain CSFR11, in which a wild-type sepJ gene was re-constructed. The same strategy was followed for construction of strain CSFR22 (using primers alr2338-37 and alr2338-55), in which the sepJ gene bears a premature stop codon generating a C-terminal deletion.

For construction of mutants bearing a sepJ gene with an internal deletion or with site-specific mutations, a first PCR step was carried out using alr2338-37 and a specific primer ("a") where nucleotide changes were introduced, and primer alr2338-38 and another specific primer ("b") that overlapped primer "a" (Table S2). After this first step, an overlapping PCR was carried out using the products of the two previous PCR reactions as template and primers alr2338-37 and alr2338-38. The products of these PCRs, which contained specific-site mutations or small deletions, were cloned into EcoRI-digested pCSV3 producing plasmids pCSFR53 to pCSFR68 (Table S2). Plasmids were transferred to the CSVM90 mutant by conjugation [42]. Clones resistant to Sm and Sp were selected, and their genomic structure in the SepJ permease region was analyzed by PCR with primers alr2338-10 (which lies within the 3' region of the construct) and alr2338-25 (which lies outside of the construct, $5^{\prime}$ from it). Clones that showed recombination in the correct chromosomal location and were segregated for the chromosomes bearing the sepJ mutations were chosen for further study. 


\section{Phenotypic characterization}

Filament length and heterocyst differentiation were analyzed by light microscopy. Cells grown in BG11 medium (in the presence of Sm and Sp for the mutants) were harvested, washed three times with $\mathrm{BG}_{1} 1_{0}$ medium and inoculated in $\mathrm{BG}_{1} 1_{0}$ medium at $1 \mu \mathrm{g}$ chlorophyll $a$ (Chl) per $\mathrm{ml}$. Micrographs were taken before inoculation and after $24 \mathrm{~h}$ and $48 \mathrm{~h}$ of incubation in $\mathrm{BG}_{1} 1_{0}$ medium. Filament length and frequency of heterocysts were analyzed using ImageJ software. Nitrogenase activity was determined as previously described [8] using the acetylene reduction assay in filaments incubated for $48 \mathrm{~h}$ in $\mathrm{BG} 1_{0}$ medium. Immunoblotting was performed as previously reported [27] using as primary antibody an antibody raised against the coiled-coil domain of Anabaena SepJ. For determining intercellular transfer of calcein, calcein staining and FRAP analysis were carried out as previously described [9]. After modelling the sequence of images using ImageJ software, the relative fluorescence was quantified and the Recovery $(R)$ coefficient was calculated as previously described [10]. To study nanopores, murein sacculi (which are made of peptidoglycan) were isolated from filaments grown in BG11 medium and visualized by electron microscopy as described previously [22].

\section{ACKNOWLEDGMENTS}

We thank Antonia Herrero (CSIC, Sevilla) for helpful discussions. FR-L and SA were recipients of FPI (Formación de Personal Investigador) fellowships/contracts from the

\section{REFERENCES}

1. Herrero A, Stavans J, Flores E (2016). The multicellular nature of filamentous heterocyst-forming cyanobacteria. FEMS Microbiol Rev 40: 831-854. doi: 10.1093/femsre/fuw029

2. Flores E, Picossi S, Valladares A, Herrero A (2018). Transcriptional regulation of development in heterocyst-forming cyanobacteria. Biochim Biophys Acta S1874-9399(17): 30344-9. doi: 10.1016/j.bbagrm.2018.04.006

3. Yoon HS, Golden JW (1998). Heterocyst pattern formation controlled by a diffusible peptide. Science 282: 935-938. doi: 10.1126/science.282.5390.935

4. Callahan SM, Buikema WJ (2001). The role of HetN in maintenance of the heterocyst pattern in Anabaena sp. PCC 7120. Mol Microbiol 40(4): 941-950. doi: 10.1046/j.1365-2958.2001.02437.x

5. Corrales-Guerrero L, Mariscal V, Flores E, Herrero A (2013). Functional dissection and evidence for intercellular transfer of the heterocyst-differentiation PatS morphogen. Mol Microbiol 88(6): 1093-1105. doi: $10.1111 / \mathrm{mmi} .12244$

6. Kumar K, Mella-Herrera RA, Golden JW (2010). Cyanobacterial heterocysts. Cold Spring Harb Perspect Biol 2: a000315. doi: 10.1101/cshperspect.a000315

7. Nürnberg DJ, Mariscal V, Bornikoel J, Nieves-Morión M, Krauß N, Herrero A, Maldener I, Flores E, Mullineaux CW (2015). Intercellular diffusion of a fluorescent sucrose analog via the septal junctions in a filamentous cyanobacterium. mBio 6(2): e02109. doi: 10.1128/mBio.02109-14

8. Burnat M, Herrero A, Flores E (2014). Compartmentalized cyanophycin metabolism in the diazotrophic filaments of a heterocystforming cyanobacterium. Proc Natl Acad Sci USA 111(10): 3823-3828. doi: $10.1073 /$ pnas.1318564111
Spanish Government. Work was supported by grant numbers BFU2014-56757-P and BFU2017-88202-P from the Spanish Government, co-financed by the European Regional Development Fund.

\section{SUPPLEMENTAL MATERIAL}

All supplemental data for this article are available online at www.microbialcell.com.

\section{CONFLICT OF INTEREST}

The authors declare no conflict of interests.

\section{COPYRIGHT}

(C) 2018 Ramos-León et al. This is an open-access article released under the terms of the Creative Commons Attribution (CC BY) license, which allows the unrestricted use, distribution, and reproduction in any medium, provided the original author and source are acknowledged.

Please cite this article as: Félix Ramos-León, Sergio Arévalo, Vicente Mariscal and Enrique Flores (2018). Specific mutations in the permease domain of septal protein SepJ differentially affect functions related to multicellularity in the filamentous cyanobacterium Anabaena. Microbial Cell 5(12): 555-565. doi: 10.15698/mic2018.12.661

9. Mullineaux CW, Mariscal V, Nenninger A, Khanum $H$, Herrero A Flores E, Adams DG (2008). Mechanism of intercellular molecular exchange in heterocyst-forming cyanobacteria. EMBO J 27(9): 12991308. doi: 10.1038/emboj.2008.66

10. Merino-Puerto V, Schwarz $H$, Maldener I, Mariscal V, Mullineaux CW, Herrero A, Flores E (2011). FraC/FraD-dependent intercellular molecular exchange in the filaments of a heterocyst-forming cyanobacterium, Anabaena sp. Mol Microbiol 82: 87-98. doi: 10.1111/j.1365-2958.2011.07797.x

11. Nieves-Morión M, Mullineaux CW, Flores E (2017). Molecular diffusion through cyanobacterial septal junctions. mBio 8: e01756-16. doi: 10.1128/mBio.01756-16

12. Mariscal V (2014). Cell-Cell joining proteins in heterocyst-forming cyanobacteria. In Flores E, Herrero A (eds) The Cell Biology of Cyanobacteria. Caister Academic Press, Norfolk, UK; p 293-304.

13. Flores E, Herrero A, Forchhammer K, Maldener I (2016). Septal junctions in filamentous heterocyst-forming cyanobacteria. Trends Microbiol 24(2): 79-82. doi: 10.1016/j.tim.2015.11.011

14. Giddings TH and Staehelin LA (1981). Observation of microplasmodesmata in both heterocyst-forming and non-heterocyst forming filamentous cyanobacteria by freeze-fracture electron microscopy. Arch Microbiol 129: 295-298. doi: 10.1007/bf00414700

15. Wilk L, Strauss M, Rudolf M, Nicolaisen K, Flores E, Kühlbrandt W, Schleiff E (2011). Outer membrane continuity and septosome formation between vegetative cells in the filaments of Anabaena sp. PCC 7120. Cell Microbiol 13(11): 1744-1754. doi: 10.1111/j.14625822.2011.01655.x

16. Lehner J, Berendt S, Dörsam B, Pérez R, Forchhammer K, Maldener I (2013). Prokaryotic multicellularity: a nanopore array for bacterial 
cell communication. FASEB J 27(6): 2293-2300. doi: 10.1096/fj.12225854

17. Omairi-Nasser A, Mariscal V, Austin JR 2nd, Haselkorn R (2015). Requirement of Fra proteins for communication channels between cells in the filamentous nitrogen-fixing cyanobacterium Anabaena sp. PCC 7120. Proc Natl Acad Sci USA 112(32): E4458-4464. doi: 10.1073/pnas.1512232112

18. Flores E, Pernil R, Muro-Pastor AM, Mariscal V, Maldener I, Lechno-Yossef S, Fan Q, Wolk CP, Herrero A (2007). Septum-localized protein required for filament integrity and diazotrophy in the heterocystforming cyanobacterium Anabaena sp. strain PCC 7120. J Bacteriol 189(10): 3884-3890. doi: 10.1128/jb.00085-07

19. Nayar AS, Yamaura H, Rajagopalan R, Risser DD, Callahan SM (2007). FraG is necessary for filament integrity and heterocyst maturation in the cyanobacterium Anabaena sp. strain PCC 7120. Microbiology 153: 601-607. doi: 10.1099/mic.0.2006/002535-0

20. Bauer CC, Buikema WJ, Black K, Haselkorn R (1995). A shortfilament mutant of Anabaena sp. strain PCC 7120 that fragments in nitrogen-deficient medium. J Bacteriol 177(6): 1520-1526. doi: 10.1128/jb.177.6.1520-1526.1995

21. Merino-Puerto V, Mariscal V, Mullineaux CW, Herrero A, Flores E (2010). Fra proteins influencing filament integrity, diazotrophy and localization of septal protein SepJ in the heterocyst-forming cyanobacterium Anabaena sp. Mol Microbiol 75: 1159-1170. doi: 10.1111/j.1365-2958.2009.07031.x

22. Mariscal $V$, Nürnberg DJ, Herrero $A$, Mullineaux CW, Flores $E$ (2016). Overexpression of SepJ alters septal morphology and heterocyst pattern regulated by diffusible signals in Anabaena. Mol Microbiol 101(6): 968-981. doi: 10.1111/mmi.13436

23. Bornikoel J, Carrión A, Fan Q, Flores E, Forchhammer K, Mariscal V, Mullineaux CW, Perez R, Silber N, Wolk CP, Maldener I (2017). Role of two cell wall amidases in septal junction and nanopore formation in the multicellular cyanobacterium Anabaena sp. PCC 7120. Front Cell Infect Microbiol 7: 386. doi: 10.3389/fcimb.2017.00386

24. Mariscal V, Herrero A, Nenninger A, Mullineaux CW, Flores E (2011). Functional dissection of the three-domain SepJ protein joining the cells in cyanobacterial trichomes. Mol Microbiol 79(4): 1077-1088. doi: $10.1111 / j .1365-2958.2010 .07508 . x$

25. Corrales-Guerrero L, Tal A, Arbel-Goren R, Mariscal V, Flores E, Herrero A, Stavans J (2015). Spatial fluctuations in expression of the heterocyst differentiation regulatory gene hetR in Anabaena filaments. PloS Genet 11(4): e1005031. doi: 10.1371/journal.pgen.1005031

26. Rudolf $M$, Tetik N, Ramos-León F, Flinner N, Ngo G, Stevanovic M, Burnat M, Pernil R, Flores E, Schleiff E (2015). The peptidoglycanbinding protein SjcF1 influences septal junction function and channel formation in the filamentous cyanobacterium Anabaena. mBio 6(4): e00376. doi: 10.1128/mBio.00376-15

27. Ramos-León F, Mariscal V, Frías JE, Flores E, Herrero A (2015). Divisome-dependent subcellular localization of cell-cell joining protein SepJ in the filamentous cyanobacterium Anabaena. Mol Microbiol 96(3): 566-580. doi: $10.1111 / \mathrm{mmi} .12956$

28. Ramos-León F, Mariscal V, Battchikova N, Aro EM, Flores E (2017). Septal protein SepJ from the heterocyst-forming cyanobacterium Anabaena forms multimers and interacts with peptidoglycan. FEBS Open Bio 7(10): 1515-1526. doi: 10.1002/2211-5463.12280

29. Jack DL, Yang NM, Saier MH Jr (2001). The drug/metabolite transporter superfamily. Eur J Biochem 268(13): 3620-3639. doi: 10.1046/j.1432-1327.2001.02265.x
30. Kaneko T, Nakamura Y, Wolk CP, Kuritz T, Sasamoto S, Watanabe A, Iriguchi $\mathrm{M}$, Ishikawa A, Kawashima K, Kimura $T$, Kishida $\mathrm{Y}$, Kohara $\mathrm{M}$, Matsumoto M, Matsuno A, Muraki A, Nakazaki N, Shimpo S, Sugimoto M, Takazawa M, Yamada M, Yasuda M, Tabata S (2001). Complete genomic sequence of the filamentous nitrogen-fixing cyanobacterium Anabaena sp. strain PCC 7120. DNA Res 8(5): 205-13; 227-53. doi: 10.1093/dnares/8.5.205

31. Rivers OS, Videau P, Callahan SM (2014). Mutation of sepJ reduces the intercellular signal range of a het $N$-dependent paracrine signal, but not of a pats-dependent signal, in the filamentous cyanobacterium Anabaena sp. Strain PCC 7120. Mol Microbiol 94(6): 1260-1271. doi: $10.1111 / \mathrm{mmi} .12836$

32. Bornikoel J, Staiger J, Madlung J, Forchhammer K, Maldener I (2018). LytM factor Alr3353 affects filament morphology and cell-cell communication in the multicellular cyanobacterium Anabaena sp. PCC 7120. Mol Microbiol 108(2): 187-203. doi: 10.1111/mmi.13929

33. Nieves-Morión $M$, Lechno-Yossef $S$, López-Igual R, Frías JE, Mariscal V, Nürnberg DJ, Mullineaux CW, Wolk CP, Flores E (2017). Specific glucoside transporters influence septal structure and function in the filamentous, heterocyst-forming cyanobacterium Anabaena sp. Strain PCC 7120. J Bacteriol 199(7): e00876-16. doi: 10.1128/JB.00876-16

34. Yeager M, Harris AL (2007). Gap junction channel structure in the early 21st century: facts and fantasies. Curr Opin Cell Biol 19(5): 521 528. doi: 10.1016/j.ceb.2007.09.001

35. Hervé JC, Derangeon M (2013). Gap-junction-mediated cell-to-cell communication. Cell Tissue Res 352(1): 21-31. doi: 10.1007/s00441012-1485-6

36. Kang J, Burten CN, Hong G (2017). Thermodynamic basis of molecular diffusion through cyanobacterial septal junctions. mBio 8(3): e00529-17. doi: 10.1128/mBio.00529-17

37. Beltramello $M$, Piazza V, Bukauskas FF, Pozzan $T$, Mammano $F$ (2005). Impaired permeability to Ins $(1,4,5) \mathrm{P} 3$ in a mutant connexin underlies recessive hereditary deafness. Nat Cell Biol 7(1): 63-69. doi: $10.1038 /$ ncb1205

38. Zhang Y, Tang W, Ahmad S, Sipp JA, Chen P, Lin X (2005). Gap junction-mediated intercellular biochemical coupling in cochlear supporting cells is required for normal cochlear functions. Proc Natl Acad Sci USA 102(42): 15201-15206. doi: 10.1073/pnas.0501859102

39. Santa Cruz A, Meşe G, Valiuniene L, Brink PR, White TW, Valiunas $\checkmark$ (2015). Altered conductance and permeability of $C \times 40$ mutations associated with atrial fibrillation. J Gen Physiol 146(5): 387-398. doi: 10.1085/jgp.201511475

40. Rippka R, Deruelles J, Waterbury JB, Herdman M, Stanier RY (1979). Generic assignments, strain histories and properties of pure cultures of cyanobacteria. J Gen Microbiol 111: 1-61. doi: 10.1099/00221287$111-1-1$

41. Merino-Puerto V, Herrero A, Flores E (2013). Cluster of genes that encode positive and negative elements influencing filament length in a heterocyst-forming cyanobacterium. J Bacteriol 195: 3957-3966. doi: 10.1128/JB.00181-13

42. Elhai J, Vepritskiy A, Muro-Pastor AM, Flores E, Wolk CP (1997). Reduction of conjugal transfer efficiency by three restriction activities of Anabaena sp. strain PCC 7120. J Bacteriol 179(6): 1998-2005. doi: 10.1128/jb.179.6.1998-2005.1997

43. Valladares $A$, Rodríguez $V$, Camargo $S$, Martínez-Noël GMA, Herrero A, Luque I (2011). Specific role of the cyanobacterial PipX factor in the heterocysts of Anabaena sp. strain PCC 7120. J Bacteriol 193(5): 1172-1182. doi: 10.1128/JB.01202-10 